\title{
GESTATIONAL LOSS: EMOTIONAL AND LEGAL ASPECTS
}

\author{
Gláucia Maria Moreira Galvão \\ Neonatology Department \\ Odete Valadares Maternity, Belo Horizonte - Minas Gerais - Brazil \\ https://orcid.org/0000-0002-0821-0147 \\ Denise Streit Morsch \\ Clinical Psychologist, Consultant for Humanized Care for the Newborn - Kangaroo Method \\ Ministry of Health, Rio de Janeiro - Brazil \\ https://orcid.org/0000-0001-5125-253X \\ Eduardo Carlos Tavares \\ Medicine Department of PUC-Minas, Betim, Minas Gerais and Psychology Department of \\ Fumec University, Belo Horizonte - Minas Gerais - Brazil \\ https://orcid.org/0000-0001-7802-2814

\section{Maria Cândida Ferrarez Bouzada} \\ Department of Pediatrics, Medicine School of Federal University of the State of Minas Gerais \\ Belo Horizonte - Minas Gerais - Brazil \\ https://orcid.org/0000-0002-7397-6931

\section{Lead Author Contact Information} \\ Gláucia Maria Moreira Galvão. Telephone: +5531983315796 - Fax: +553132275921 \\ E-mail: gmmgbh@gmail.com. Address: Rua Maranhão, 1061/apto. 1001, Funcionários - Belo \\ Horizonte, MG - Brazil - CEP 30150-331

\section{Article Translator \\ Steven Eric Byrd} \\ Department of Society, Culture, and Languages, University of New England, \\ Biddeford/Portland, Maine, USA
}

\begin{abstract}
This study attempts to verify the conditions of mothers who have gone through gestational loss. It is designed according to semi-structured interviews of affected mothers. Through semistructured recorded interviews, directed questions were asked to ascertain perceptions that they were living through at that moment, about their adaptation to daily life, and about their mourning process and the quality of their professional activities. From the interviews, eight categorizations were created: symptoms of mourning; the time to return to work and daily routines; lack of societal recognition of mourning; mourning and spirituality; seeking of healthcare support; the fathers' pain; the need of someone; who is this baby? And the following feelings were documented from the interviews: feelings of losing control of one's life; broken dreams; feelings of incompleteness, guilt, and personal defeat; feelings of inferiority as a woman; subjective losses; losses in identity and eroticism; a woman's role in society. Lastly, the
\end{abstract}


study examines how gestational loss is unrecognized and unsupported by legislation, exposing a weakness in workers' rights and unequal treatment regarding gender.

Keywords: Gestational Loss, Mourning, Women's Health, Patient-Centered Care, Humanizing Care.

\section{INTRODUCTION}

The frequency of gestational loss occurs in $15-20 \%$ of pregnancies of up to 22 weeks. However, the subsequent implications are neglected and underestimated by political leaders, the media, society, and even by the healthcare sector (Frøen et al., 2016). In 2013, the World Health Organization defined the concept of abortion as being the interruption of gestation with a fetus of under 500 grams or with a gestational age of less than 20 weeks (Cardoso, 2020).

Gestational loss is a topic that deserves more attention, as it carries with it a particularly profound pain for the mother as well as for her partner, and includes challenges for conjugal and familial relationships, emotional and psychic distress, a general loss of interest in life and in the other children, and in the professional lives on the part of women (Frøen et al., 2016). Galdet et al. (2010) note intense psychological suffering during a pregnancy following gestational loss and highlight the need for clinical and psychosocial care when such losses occur - a form of healthcare that should be continued until the birth of the woman's next child. Recent research has called attention to this topic, as it is one which causes the families involved significant suffering, though generally overlooked (Frøen et al., 2016; Heazell et al., 2016; Horton, 2016; Aguiar; Zornig, 2016).

Neonatal loss is, in the majority of cases, unexpected and unforeseen, and occurring frequently during a normal pregnancy (Brownlee; Oikonen, 2004). These characteristics raise the feeling of shock on the part of the parents, further raising the difficulty of acceptance of the loss, and given the sudden nature, impede that family members can prepare emotionally, and therefore unable to mobilize resources and coping strategies (Callister, 2006).

Generally speaking, the male partner rebounds faster with his daily routine and his professional life (Callister, 2006; Jenkins; Heustis, 2005).

The organization of healthcare systems for the care of women that suffer gestational losses, and the care offered by healthcare professionals to affected families, is an important gauge for the general performance of a healthcare system, and one which also can contribute to the improvement of the resilience and morale of the workforce of those undergoing mourning (Homer; Malata; Tem Hoope-Bender, 2016).

Pre-natal health is a crucial biological need for the long-term health of life, and so specific actions are therefore necessary in the areas of healthcare and law: for example, the formulation of legal policies and procedures, and the monitoring and research of effective, quality interventions following gestational losses (Aguiar; Zornig, 2016).

That said, research on this topic is generally scarce. As such, the goal of this study is to provide some qualitative data through the analysis of partially structured interviews with mothers that suffered gestational losses with less than 22 weeks of pregnancy. Moreover, the study aims to better understand the emotions expressed in the mothers' speech, and better understand their conditions as they return to their daily lives and professional activities.

\section{METHODOLOGY}

The present research uses a qualitative, longitudinal approach, by means of two semi-structured interviews conducted with parents who suffered gestational losses with less than 22 weeks of 
pregnancy in the Maternidade Odete Valadares da Fundação Hospitalar de Minas Gerais, in the high-risk obstetrics sector, in Belo Horizonte, Minas Gerais, Brazil, from February to October 2019. The initial contact with the parents was realized during internment in the maternity ward, within the first 24 hours following gestational loss. At this moment, the first interview was conducted, and data were collected from their clinical records, consisting of previous and current obstetrics data of the mother, which serve as part of the data analysis. The second interview was realized one month following the gestational loss at the residence of the patient or at a place chosen by her. In this interview, directed questions were used to capture the perceptions of the moment, perceptions regarding their adaptation to daily routines following their losses, as well as perceptions about the mourning process, and regarding the quality of healthcare offered to them. From the directed questions a series of symptoms was discovered, which generated a list of categories. Following these categories, scholarly literature was consulted to verify if there was reference to each one.

To ensure privacy and guarantee anonymity of each participant in this study, numbers were utilized for all the interviewees (i.e. Mother $1=\mathbf{M} \mathbf{1}$ ). All interviews and transcriptions were undertaken by the authors in Portuguese and have been translated into English herein.

\section{Data Analysis}

The analysis of the interviews was undertaken by means of careful listening and reading of the narratives, including the significant aspects that were categorized into nuclei of feelings or emergent properties.

\section{Ethical Aspects}

This case study was approved by the Ethics Commission of the institute where the research was conducted, and also approved by the Committee of Ethics in Research by the Universidade Federal de Minas Gerais, in Belo Horizonte, Brazil. Research code: $n^{\circ}$ ETIC 3.082.705.

\section{Participants \\ Inclusionary Criteria}

Mothers who suffered spontaneous gestational losses with less than 22 weeks of pregnancy. All willfully signed an agreement titled "Termo de Consentimento Livre e Esclarecido" ("Explained Terms of Willful Consent') for this study, and whose partners or legal representatives also willfully agreed to participate and signed the same agreement.

Initially there were 34 mothers who fulfilled the inclusionary criteria and have been included in this study. All the mothers agreed to a second interview 30 days for following their gestational loss; however, only 12 of which returned and were interviewed in a place of their choosing. The demographic data of the 12 mothers that participated in the second interview are found below in Table 1 .

\section{Exclusionary Criteria}

Parents who were not residents in the region; mothers pregnant with twins who lost one of the twins; parents with documented psychiatric illnesses (i.e., psychosis, schizophrenia, panic syndrome, or other psychiatric pathologies); parents with documented cognitive deficiencies; legal abortion; mothers with a history of post-partum depression or fathers with a history of depression. 
Table 1. Demographic data of 12 women who lost children, February-October 2019.

\begin{tabular}{|c|c|c|c|c|c|c|c|c|}
\hline Mother & Age & Education level & $\begin{array}{c}\text { Formal } \\
\text { work }\end{array}$ & Pregnancies & $\begin{array}{c}\text { Living } \\
\text { children }\end{array}$ & $\begin{array}{l}\text { Age of the baby } \\
\text { at time of loss } \\
\text { (in weeks) }\end{array}$ & $\begin{array}{c}\text { Presence } \\
\text { of a } \\
\text { companion }\end{array}$ & $\begin{array}{c}\text { Presence } \\
\text { of the } \\
\text { father }\end{array}$ \\
\hline M1 & 27 & Incomplete High School & Yes & 2 & 1 & 9,1 & Yes & No \\
\hline M2 & 36 & Graduate School & No & 2 & 0 & 16 & Yes & No \\
\hline M3 & 27 & Incomplete High School & Yes & 2 & 0 & 8,5 & Yes & Yes \\
\hline M4 & 37 & High School & Yes & 3 & 1 & 7 & No & No \\
\hline M5 & 34 & Incomplete Middle & No & 3 & 1 & 19,3 & Yes & Yes \\
\hline M6 & 39 & School & No & 3 & 1 & 11,6 & Yes & Yes \\
\hline M7 & 26 & University & No & 1 & 0 & 11 & No & No \\
\hline M8 & 25 & High School & No & 1 & 0 & 12 & Yes & No \\
\hline M9 & 40 & High School & No & 2 & 1 & 9,4 & Yes & No \\
\hline M10 & 29 & Incomplete High School & Yes & 3 & 1 & 11,6 & No & No \\
\hline M11 & 35 & Middle School & Yes & 2 & 1 & $* 285 \mathrm{~g}$ & No & No \\
\hline M12 & 20 & University & Yes & 1 & 0 & 12,1 & Yes & Yes \\
\hline
\end{tabular}

\section{RESULTS AND DISCUSSION}

An analysis of the interviews realized by means of careful listening and reading of the narratives were organized into nuclei of meaning or emerging properties (Neale, 2016), of which eight central categories have been identified and described in Table 2.

Table 2. Categorization

\begin{tabular}{|l|l|}
\hline \multicolumn{1}{|c|}{ Categories } & \multicolumn{1}{|c|}{ Descriptions } \\
\hline Symptoms of mourning & $\begin{array}{l}\text { Narratives of guilt, failure, shame } \\
\text { Nostalgic aspects, a search for evidence of the baby } \\
\text { Emotional symptoms (i.e. difficulty to fall asleep, problems } \\
\text { with concentration, irritability, etc.) } \\
\text { Bodily changes and experiences related to pregnancy } \\
\text { Relational issues with others (i.e. projections onto other } \\
\text { mothers) }\end{array}$ \\
\hline Returning to work and daily routines & \\
\hline Lack of societal recognition of mourning & \\
\hline Mourning and spirituality & \\
\hline Need of healthcare support & \\
\hline $\begin{array}{l}\text { Fatherly pain (i.e. from the point of view of the } \\
\text { mother and as narrated from the father) }\end{array}$ & $\begin{array}{l}\text { The need of someone (i.e. presence of the father of } \\
\text { the child or of the mother's mother) }\end{array}$ \\
\hline $\begin{array}{l}\text { Who is this baby? (i.e. a place denominated by the } \\
\text { family, an abstract entity that they are unable to } \\
\text { name) }\end{array}$ & \\
\hline
\end{tabular}

\section{Discussion of the categorizations}

1) Symptoms of mourning

a) Narratives of guilt, failure, shame

This type of mourning is peculiar, as it emits experiences relating to the pregnancy, to the loss, to the types of self-care; hence, it implies a deep-seeded psychological aspect related to the beginnings and creation of life. It can be inferred that this is truly a physical type of mourning: the emotional pain is deeper than other symptoms, as it is connected intimately to the body, touching the essence of female identity, and thus harnessing a feeling of 
failure at being a mother, and at being a woman generally. It further carries with it a devaluing of oneself image, and a feeling that her body was unable to properly function, or a belief that she is incapable of performing her proper biological and conjugal role (Stirtzinger; Robinson; Stewart, 1999).

In our society, the role of maternity is viewed as a natural function of a woman, and hence being a mother is a full realization of the female gender role. As such, when a woman is incapable of creating healthy life as part of her "natural function," she is often overcome by a sense of inferiority and incompleteness.

Note the following evidence documented during the interviews:

"I have had much difficulty in seeing myself in the mirror in the last days. I look in the mirror... But I don't see myself, it's like I'm empty, that's what it feels like. Just yesterday I asked my husband, and I was really afraid to ask; I asked him: if I am unable to give you any children, will you still stay with me?" (M 2)

'It's not a type of physical pain anymore, it's an emotional pain, that's it... you feel [emotional] pain. It's a pain that doesn't go away. You feel guilty deep down, even knowing that I didn't do anything to cause this.” (M 1)

"Having to tell everyone, to explain, to listen to people accusing you, that something is wrong with you, that you are the problem, that I have to get treatment, to tell people - that is hard. (Cries)" (M 3)

b) Nostalgic aspects, and a search for evidence of the baby

Nostalgic aspects are a type of memory associated with the mother's loss. Some parents, in fact, view the loss as if it were still alive, a type of nostalgic object in which they can animate and reanimate. This type of nostalgia creates a situation for the parents in which the absent baby still has a place in their lives (Soubieux, 2014). Note the evidence of this symptom:

"I dreamed, before I found out that my pregnancy was anembryonic, that it was a white girl, just like my partner, with big eyes, you know? A beautiful baby girl. Then I realized it was just a dream." (M 10)

"I go to college; I go to work. But it's not the same thing. It isn't... I keep thinking that now I would be so many months [pregnant]... (cries). Even though I hadn't planned on getting pregnant, but it was my daughter... (cries)" (M 12)

\section{c) Emotional symptoms}

Gestational loss abruptly ends the pregnancy, which creates an overwhelming sense of anguish. For any pregnant woman, the loss of a child is a painful experience, even in the initial months of gestation. The interviews revealed a sense of sadness, surprise, and impotence from the loss: 
"It's like this: I can't focus on anything else. At every moment I keep thinking about it, practically 24 hours." (M 5)

"I became somewhat - speaking and thinking - I'm here and I'm not here, because that's what your head is like. It's overwhelming. Because [you ask yourself] what?, where?, when? And it's not supposed to be like that." (M 9)

Mothers often connect with their own mothers, addressing memories of womanhood, sexuality, and also traits from their past lives of when they were babies themselves being nursed and cared for. Note the following evidence from this interviewee:

"And even if I didn't want [my mother] in the beginning (sighs), I am grateful now for her coming. I think I discovered the love that my mother feels for me, even though I never had the chance to hold a baby at my breast, I didn't get to have that same type of touch, right? Our touch, I think, was more of a soulful one, right? (Cries) And even though I didn't get to have that same touch, I am thankful that she came. I had very magical moments with her. I felt very loved when she was here. My mother showed she loved me a lot." (M 8)

d) Bodily changes and experiences related to pregnancy

There is a perception by a woman that her body has changed, her breasts have grown, and her pelvis has lengthened, thereby leaving traces that the baby was alive in her uterus. These experiences with bodily changes become committed to memory. Note the following evidence from these interviewees:

"Even though they said that my pregnancy was anembryonic, it's still a pregnancy, your body changes, your emotions change. It messes with your head, you feel a baby inside you, and then you're not able to nurture the baby. You get sad, thinking: 'gosh, my body has changed, my belly has started to grow, I gained weight. I was pregnant, but just wasn't able to have the baby." (M 10)

"When I shower, I look at my belly, sometimes I stick out my belly (pauses to cry), to think about and to feel the sensation of being pregnant. (Cries)" (M 3)

\section{e) Relational issues with others}

Defey (1992) notes that it's understandable that feelings of jealousy in relation to other women with healthy children - perceptible or not - may also emerge, bringing with it psychological consequences that are difficult to manage emotionally. This can bring a woman to feel emotions that are deeply feared: a disease limiting human potential, an insanity that alienates people from one another, and, finally, the view of death as an inevitable and irreversible end of the life cycle. Note the following evidence:

"I was locked in, I stayed home, more than 15 days. I wasn't able to go out into public. I wasn't able to be around people. When I saw people, I didn't want them to see me." (M 5) 
"I saw mothers going out with a baby, and I, by myself, with a medical report. With a... the only thing I had left was the ultrasound of her, I only have the ultrasound (cries). And I got home, returned with nothing. Returning from the hospital without a baby, with your husband, just us two, what happens then? The suffering and despair that a mother can go through." (M 5)

"Since I work in a gynecological clinic, when I would see a mother (whimpers, pauses to cry). When I would see a mother breastfeeding (crying as she speaks), I would pick up a baby so I wouldn't cry in front of her. Then... I began to think, why don't I have a baby... in my arms? Why did this just happen to me?" (M 3)

"I saw another mother coming [into the gynecological clinic], coming to deliver her baby... When I heard the baby's cry, I broke down and cried a lot.” (M 3)

2) Returning to work and the daily routine

Getting back to one's daily routine (which focuses on a way of dealing with life without being loved) and its oscillation (which is an alternation between the one and the other) involve returning to life's daily tasks, doing new things, and distracting oneself (Stroebe; Schut, 1999). These tasks are potent tools to help those in the mourning process, as either a means or an end (Dahdah et al., 2019). Evidence of this search for occupying oneself, of seeking refuge in daily tasks and work during the mourning process, can be seen in these following interviewees:

"For me it was good [to go back to work], because of the environment at home. It's harder when you're at home with your husband, because of the memory, which is worse. I think going back to work was good." (M 4)

"I returned to work after two weeks. I went back. I was just at home doing nothing for a week, and then I decided to go back. And it was really good. It helps to distract you, you get back to living your life again." (M 7)

"The 15 days I was at home I didn't get over it. Because I was by myself and I couldn't think about anything else, I just kept thinking about her, I just stayed in bed, crying, crying. When I went back to work it was a relief." (M 3)

"I went back [to work] 14 days afterward. In the beginning I thought I was doing well, and then later one day, when I began to work, I saw that I really was not emotionally very well. So, emotionally speaking, I think my level of concentration at work was not the same as before... So, 15 days are not really sufficient for the mourning process.” (M 11)

"That is why I'm saying, I came back to get distract myself because I got distracted a little, it's good to be at home, because of the rest. Because the doctor gave me 40 days of rest, but I couldn't handle staying at home anymore. So, I went back to work with 15 days. I've never seen 15 days go so fast before in my life. And now after that time that I began to get my head back together." (M 1) 
“(Crying) I don't even know what to say, it's not easy, it's not easy going back to work, but it was good for me to go back, to work, to study. I think that the more you occupy your mind with other things it's better. I just wanted to forget everything. Everything. I just wanted to forget everything that happened. (Cries)" (M 12)

\section{3) Lack of societal recognition}

When the loss of a child happens before it's born, in the eyes of society this occurrence, for the most part, is a non-event. That is, a child that wasn't born never existed. The general idea is that the intensity and duration of mourning is proportional to the time that the parents had with the children. Given that the time was short in this instance, so should the mourning be. However, contrary to such views, what we see is that the mourning process can be worse for parents in instances when the children were never present in their lives. Couples frequently find themselves isolated and misunderstood in terms of their feelings of sadness (Soubieux, 2014). Note the following evidence:

"So, it's funny that I used to judge people who lost babies that were only months, or even days, as silly. Now that I am going through this, I know that it isn't silly, it's actually very hard. I used to see people crying, and thinking, 'Gosh, how silly, if it had been older, ok.' But now I understand." (M 9)

"It's over now, it's been a month now. Not everyone thinks about it. For me, no, not seeing my belly getting bigger, not being able to buy baby things. For me, it has been very hard." (M 3)

\section{4) Mourning and spirituality}

One mourning strategy that was observed in our interviews was the search for explanations in spirituality, seeking consolation in the idea that the loss of the child was "deemed by God." Note the following:

"People that believe in God have an easier time dealing with life's issues... I am no longer afraid, because we believe in God, right? So, when you believe in God, you know that it was God's plan; perhaps something would happen in the future. In the moment, you're devastated, right? But afterward my belief in God became strong... I found a refuge, because you have to have a refuge. People without a refuge are unable to overcome [their loss].” (M 7)

"My mother is follower of spiritualism, and the place downtown where she goes, they speak a lot about that." (M 9)

"And now we'll see what's in store, what God has planned for us. I'm very scared." (M 2) 
5) Need for healthcare support

One often overlooked consideration for gestational loss is that a woman has a period of internment in the hospital, which is often difficult and painful for her given that she is in a hospital environment and often surrounded by pregnant women - mothers who have just given birth, as well as newborn babies. Nazaré et al. (2013) note that women in these conditions become physically and emotionally weakened, and therefore need support and attention by a whole network, including healthcare professionals. A humanized support system in the context of gestational loss should not be only for tending to physical pain, but also present to tend to psychological pain, also essential for the mourning process (Worden, 2008). The importance of this aspect is evidenced below:

"And then a feeling of abandonment overcame me. You know, it's difficult for a mother that lost her baby, to be with the baby inside her belly, to be in the same place with women who are about to give birth, with women who are having contractions but know that the pain is going to pass and are soon going to have a child in her arms. I thought that was cruel. Because I knew that my baby was going to come out and I wouldn't get to hold him. I felt dead inside there [in the hospital]. (Cries)" (M 2)

"The worst part here [in the hospital] was to see babies being born and know that mine wasn't going to be born. (Cries)" (M 12)

6) Paternal suffering

In relation to the question of gender, some studies regarding gestational loss indicate that, since the woman is the one who carries the baby in her womb, she carries a greater sense of guilt with the loss in comparison to the man (Defey, D. et al., 1992). Fathers, according to McCreight (2004), typically show a more controlled response toward the loss due to the need to be "strong" and offer support to the woman.

The interviewed women highlighted the pain from their companions:

“The pregnancy is not just a woman's but a man's as well, right? So, there is a lot of suffering. And the father ends up suffering, too." (M 7)

"Pregnancy doesn't begin with only one person; there are two people involved. Why do women only have rights [to a work leave to mourn]? Women carry the babies inside them. But men form part of it as well." (M 7)

"How is it that a father doesn't get to stay with his wife? The wife just lost a child. And the child is his, too, it's not just the wife's. Why can't he stay at home at least one day? What about his feelings?" (M 5)

7) The need of someone

The presence of family members plays an important role in supporting women that lost children. To be able to count on the support of the dearest and closest people is important 
at that moment. The father of the child has been described as an essential figure (Conway; Russell, 2000). But the mother's mother is also a central figure. This is evidenced below:

"If he hadn't been there, it would have been... it would have been worse, my suffering would have been more for sure." (M 3)

"You can have your entire family, but the only person that you want to talk to is the father [of the child], I want to talk to him, I feel I have more freedom to talk to him about the issue because he also is going through the same thing, not as intense as me, but he is by my side and he is going through the same things that I'm going through, and that's why I think he should have some time off as well, and he has nothing, he had to work." (M 1)

"It was really awful because have the father [of the child] by your side, you wouldn't have been less sad, because it is very sad. But you would feel more secure, more supported. At that moment you want support, someone at your side." (M 6)

Who is this baby?

It needs to be understood that gestational loss implies, on the part of the parents and family, an abandonment of a family project - even when this occurs in the first weeks of pregnancy. For many families, the fetus not only had a tentative name, depending on the gender, but also had a family heritage in terms of projects and investments (Aguiar; Zornig, 2016). According to Aguiar and Zornig (2016), the parents lost the promise of a child, the promise of paternity and maternity, and the death of this child represented someone who was never totally independent from them and from their plans. These feelings appeared in the interviews below:

"It felt like it was going to be a girl. But I don't know." (M 9)

"The baby was going to named Maria Eduarda or Lucas - which is what my husband chose if it were a boy. (Cries). But it's really hard." (M 3)

Soubieux (2014) highlights that child lost during gestation in the psyche of the parents will not be the same. The mourning period will be the time of coming to terms with the life that existed and then ceased to exist. When mourning is realized, it can generate a surprising psychic reconstruction. And the gestational loss is paradigmatic, whereby it can be revived in future pregnancies (for the parents and for people close to them). In the specific case of gestational loss, the lack of recognition - and a lack of a support network - can transmit a message to the parents that the loss is unnecessary, and thereby creating further difficulties (Public Health Agency of Canada, 2000).

The parents must adjust to the diverse levels associated with the loss: external (relative to the day-to-day functioning of the person), internal (referring to the identity of the person and the diverse roles that she or he assumes, namely mother and father, the absence of other children, roles the person may not know how to continue, or not, to assume) and spiritual (involving beliefs, values, and assumptions of people). Finally, the mourning 
process is concluded when the person is capable of emotionally integrating the loss of the child and continuing on with her/his life. This does not imply ending the relationship with the lost child, but instead recreate it in a way that allows the parents to cope with the loss.

The symptoms that come with loss are more intense in the first months following the occurrence, though varying regarding the diversity and intensity, and being highly variable (Nazaré, 2012; Kavanaugh; Wheeler, 2003). This encompasses the relationship between mother and father, the connection with the child (i.e. the level of desire of wanting a child), the length of the pregnancy, and the existence of past losses. Finally, the familial and social support available, the type of relationship with other family members, and the attitudes of healthcare professionals are assumed to be the most relevant factors in coping with the loss.

To simply not worry about what happens to the mother after she leaves the hospital creates a "conspiracy of silence." A woman who has suffered a gestational or post-partum loss should have the right to speak openly about what happened to her, to speak about her frustrations and feelings of guilt and impotence; not to confront such immense sadness, but to support her and her family's life after the loss. The family needs to be taken care of in a contingent manner and not excluded from the healthcare team.

Hence, it is important to construct, develop, and nurture a support network and partnerships of outreach to improve the healthcare service to patients and their loved ones who may be undergoing psychosomatic, affective, psychological and/or spiritual suffering caused by gestational loss. Furthermore, a new perspective regarding fetal and perinatal death within the healthcare profession needs to be taken into consideration. Specific actions by healthcare and legal professionals, new legislative policies, monitoring and research for effective, fact-based interventions for people following gestational losses are necessary to pursue for the future (Aguiar; Zornig, 2016).

The interviews also have offered evidence that the suffering of fathers following a gestational loss is often ignored. But, in fact, the couple suffers together. The inexistence of the worker leave policies for fathers after a gestational loss demonstrates a gender inequality, and furthermore shows not only the invisibility of paternal suffering but also the invisibility of the unborn child. However, paternal pain is legitimate independent of how long the pregnancy lasted. New directives of support, including support for gestational loss as a basic indicator of healthcare quality, are fundamental in this respect.

\section{CONCLUSIONS}

The documented accounts of mourning mothers in this study show the premature tendency to return to daily activities and work as a coping strategy for mourning. Instead, we underscore the importance of individualizing healthcare for return to such activities on a case-by-case basis. Another strategy we have documented in the interviews is the coping through religion and/or spirituality: that is, strategies which capture feelings of hope and faith, independent of the religion that they may practice.

In the speech of the interviewees, feelings related to the female role in society and her identity as a woman are revealed, the sensation of losing control of one's life and body, broken dreams, feelings of incompleteness, guilt, personal defeat, and feelings of inferiority. The evidence also presents that women do not just suffer the loss of a child, but must also learn to navigate a new reality: a new relationship with herself and her body, with other women, with the 
idea of maternity, with the idea of being an ideal woman, and so forth. These are significate topics that offer outlets for more research in terms of gestational loss and mourning.

There is evidence presented herein that current labor laws regarding gestational loss - in special for fathers - have not been recognized and supported. However, this pain can be intense and is not exclusive to women, but to the couple. Having one's partner during this period creates a mutual support system, and is fundamental to the mourning process following gestational loss. Mothers going through mourning cite the importance of having someone nearby during their time of internment in the hospital for support and to talk about their feelings, which helps them to not feel isolated and unsupported - the chosen person typically being their partner or their mother.

We have verified the need for intervention to such patients on behalf of healthcare teams and other related networks. Training of functionaries who work in these areas is essential. A multidisciplinary approach is desirable to tackle the problem of perinatal mourning and prevent its harmful effects. It is also important to deepen our knowledge of this problem, to discover the specifics and nuances of gestational loss so to offer better, more adaptable healthcare systems, adjusted on a case-by-case basis, whereby there is not improvisation but operating in a systematic and long-term manner over the duration of the mourning process. It is furthermore important to construct, develop, and create a supportive network and partnerships to better tend to patients and their loved ones who may be affected by psychosomatic, affective, psychological and/or spiritual distress following gestational losses.

In short, a new and holistic perspective about gestational loss needs to be examined and acted upon. Such medical interventions are fundamental so that higher quality healthcare is offered to patients and their family members. This should include improving the physical space where mothers are placed during their time in the hospital, and better training for healthcare professionals, so to care for these mothers in the best, most humane manner possible. Such care should also include basic healthcare units, creating strategies with the family during pre-natal care and following the loss, constructing a comprehensive therapeutic strategy capable of making a humanized form of care, whereby there are spaces for women to share their painful feelings during the mourning period following gestational loss. And, finally, that this becomes a normalized practice in healthcare services.

\section{Disclosure of interest}

The authors report no conflict of interest.

\section{REFERENCES}

Aguiar, H., \& Zornig, S. (2016). Fetal grief: interruption of a promise. Estilos da Clínica, 21(2),264-81. http//dx.doi.org/0.11606/issn.1981-1624.v21i2p264-281.

Brownlee, K., \& Oikonen, J. (2004). Toward a theoretical framework for perinatal bereavement. British Journal of Social Work, 34(4), 517-529. https://doi.org/10.1093/bjsw/bch063.

Callister L. C. (2006). Perinatal loss: a family perspective. The Journal of Perinatal \& Neonatal Nursing, 20(3), 227-236. https://doi.org/10.1097/00005237-200607000-00009. 
Cardoso, B. B., Vieira, F. M. S. B., \& Saraceni, V. (2020). Abortion in Brazil: what do the official data say?. Cadernos de Saúde Pública, 36(Suppl 1), e00188718. https://doi.org/10.1590/01002-311x00188718.

Conway, K., \& Russell, G. (2000). Couples' grief and experience of support in the aftermath of miscarriage. The British journal of medical psychology, 73 Pt 4, 531-545. https://doi.org/10.1348/000711200160714.

Dahdah, D. F., Bombarda, T. B., Frizzo, H. C. F., \& Joaquim R. H. V. T. (2019). Systematic review about bereavement and occupational therapy. Cadernos Brasileiros de Terapia Ocupacional, 27(1), 186-196. https://doi.org/10.4322/2526-8910.ctoar1079.

Defey, D., Diaz Rossello, J. L., Friedler, R., Nuñez, M., \& Terra, C. (1992). Duelo por un niño que muere antes de nacer. In Duelo por un niño que muere antes de nacer (pp. 157-157).

Frøen, J. F., Friberg, I. K., Lawn, J. E., Bhutta, Z. A., Pattinson, R. C., Allanson, E. R. ... \& Lancet Ending Preventable Stillbirths Series study group (2016). Stillbirths: progress and unfinished business. Lancet (London, England), 387(10018), 574-586. https://doi.org/10.1016/S0140-6736(15)00818-1.

Gaudet, C. (2010). Pregnancy after perinatal loss: association of grief, anxiety and attachment. Journal of Reproductive \& Infant Psychology, 28(3), 240-251. https://doi.org/10.1080/02646830903487342.

Heazell, A., Siassakos, D., Blencowe, H., Burden, C., Bhutta, Z. A., Cacciatore, J., ... \& Lancet Ending Preventable Stillbirths investigator group (2016). Stillbirths: economic and psychosocial consequences. Lancet (London, England), 387(10018), 604-616. https://doi.org/10.1016/S0140-6736(15)00836-3.

Homer, C., Malata, A., \& Ten Hoope-Bender, P. (2016). Supporting women, families, and care providers after stillbirths. Lancet (London, England), 387(10018), 516-517. https://doi.org/10.1016/S0140-6736(15)01278-7.

Horton, R., \& Samarasekera, U. (2016). Stillbirths: ending an epidemic of grief. Lancet (London, England), 387(10018), 515-516. https://doi.org/10.1016/S01406736(15)01276-3.

Jenkins, M., \& Heustis, J. (2005). Companioning at a time of perinatal loss: a guide for nurses, physicians, social workers, chaplains and other bedside caregivers. Fort Collins: Companion Press.

Kavanaugh, K., \& Wheeler, S. R. (2003). When a baby dies: caring for bereaved families. In C. Kenner, J. W. Lott (Eds.), Comprehensive neonatal nursing: a physiologic perspective (pp. 108-126). Philadelphia: WB Saunders. 
McCreight, B. (2004). A grief ignored: narratives of pregnancy loss from a male perspective. Sociology of Health \& Illness, 26(3), 326-350. https://doi.org/10.1111/j.14679566.2004.00393.x.

Nazaré, B., Fonseca, A. L. M., \& Canavarro, M. C. (2013). Adaptive and maladaptive grief responses following TOPFA: actor and partner effects of coping strategies. Journal of Reproductive and Infant Psychology, 31(3), 257-273. https://doi.org/10.1080/02646838.2013.806789.

Nazaré, B., Fonseca, A., \& Canavarro, M. C. (2012). Grief following termination of pregnancy for fetal abnormality: does marital intimacy foster short-term couple congruence? Journal of Reproductive and Infant Psychology, 30(2), 168-179. https://doi.org/10.1080/02646838.2012.693154.

Neale, J. (2016). Iterative categorization (IC): a systematic technique for analysing qualitative data. Addiction, 111(6), 1096-1106. https://doi.org/10.1111/add.13314.

Public Health Agency of Canada. (2000). Family-centred maternity and newborn care: national guidelines. Ottawa: PHAC.

Romesín, H. M., \& Verden-Zöller, G. (2012). The origin of humanness in the biology of love. Exeter: Pille Bunnell.

Soubieux, M. J. (2014). Le deuil périnatal, un impensable à penser. Le Carnet PSY, 185(9), 2224. https://doi.org/10.3917/lcp.185.0022.

Stirtzinger, R. M., Robinson, G. E., Stewart, D. E., \& Ralevski, E. (1999). Parameters of grieving in spontaneous abortion. The International Journal of Psychiatry in Medicine, 29(2), 235-249.https://doi.org/10.2190/UDW4-2EAG-1RTY-D1Y4.

Stroebe, M., Schut, H. (1999). The dual process model of coping with bereavement: rationale and description. Death studies, 23(3), 197-224. https://doi.org/10.1080/074811899201046.

Williams, H. M., Topping, A., Coomarasamy, A., \& Jones, L. L. (2020). Men and miscarriage: a systematic review and thematic synthesis. Qualitative Health Research, 30(1), 133-145. https://doi.org/10.1177/1049732319870270.

Worden, J. W. (2008). Grief counseling and grief therapy: a handbook for the mental health practioner. 4a ed. New York, NY: Springer.

\section{Copyrights}

Copyright for this article is retained by the author(s), with first publication rights granted to the journal. This is an open-access article distributed under the terms and conditions of the Creative Commons Attribution license (https://creativecommons.org/licenses/by/4.0). 